\title{
ATRAPADO EN ENSOÑACIONES MESMÉRICAS. ESTUDIO DE LOS ELEMENTOS ESOTÉRICO-FANTÁSTICOS EN AURA DE CARLOS FUENTES*
}

\author{
TRAPPED IN A MESMERIC DREAM STATE. A STUDY OF THE ESOTERIC \\ AND FANTASTIC ELEMENTS IN CARLOS FUENTES' AURA
}

Daniele ARCIELLO

Universidad de León

arciellod@gmail.com

\begin{abstract}
Resumen: El presente estudio surge con la pretensión de analizar los aspectos de tintes esotéricos y fantásticos más llamativos en Aura de Carlos Fuentes. Pese al acervo de solventes ensayos dedicados a este campo de investigación, el valor de la obra es indudablemente merecedor de exámenes ulteriores que realcen su trascendencia en temáticas muy actuales. El protagonista del relato en efecto emprende un camino que, en consonancia con los personajes de la literatura horrífica tradicional, constituye una certera alegoría del recorrido existencial, en el marco de la lucha entre la lumbre del ser racional y las tinieblas de lo inexplicable. El concepto dicotómico luz-sombra se traduce en el empleo de resortes no miméticos, que se fusionan con el ocultismo y la ritualidad apotropaica. Para examinar cabalmente el armazón fantástico que vertebra el texto, hemos de profundizar en su contenido. Nuestro objetivo consiste en resaltar la narración cautivadora de un escritor capaz de que tanto el lector como el protagonista queden dominados por el encantamiento de la bruja.
\end{abstract}

Palabras clave: Aura; Carlos Fuentes; elementos fantásticos; esoterismo; literatura hispanoamericana del siglo XX.

Abstract: This essay aims to analyse the most relevant esoteric and fantastic aspects in Aura by Carlos Fuentes. Despite the great amount of admirable study regarding this area of interest, the value of this work undoubtedly deserves more consideration to highlight its relevance in current issues. As a matter of fact, the protagonist of the tale takes a path that, keeping in line with what is typical for characters in traditional horror literature, is an effective allegory for the existential journey in the

\footnotetext{
* Agradecimientos al profesor Francisco Javier Ordiz Vázquez por sus sugerencias y correcciones y a la profesora María Asunción Sánchez Manzano por la revisión de las citas en latín y por el interés en la temática brujesca.
} 
30 | Tropelías. Revista de Teoría de la Literatura y Literatura Comparada, 32 (2019)

Daniele Arciello

context of the struggle between the enlightenment of the rational being and the darkness of the inexplicable. The dichotomous conceptualisation of light and darkness is expressed by a non-mimetic narrative that combines itself with occultism and apotropaic rituals. In order to exhaustively analyse the ensemble of fantastic literary elements that undergird the text, we must delve deep into its contents. Our aim is to emphasise the captivating storyline of a writer capable of compelling both the reader and the main character to be dominated by the spell of the witch.

Key words: Aura; Carlos Fuentes; esoterism; fantastic literature elements; twentieth century Spanish American literature. 
Vit-on jamais au bal une taille plus mince?

Sa robe exagérée, en sa royale ampleur, S'écroule abondamment sur un pied sec que pince Un soulier pomponné, joli comme une fleur. [...] Viens-tu troubler, avec ta puissante grimace, La fête de la Vie? ou quelque vieux désir, Eperonnant encor ta vivante carcasse,

Te pousse-t-il, crédule, au sabbat du Plaisir? Au chant des violons, aux flammes des bougies, Espères-tu chasser ton cauchemar moqueur, Et viens-tu demander au torrent des orgies De rafraîchir l'enfer allumé dans ton coeur? ${ }^{1}$ Charles Baudelaire, Danse macabre

1

\section{Introducción}

La complejidad de un texto publicado en la década de los sesenta, que redactó un escritor de los más destacados entre los representantes del Boom, ha hecho que la crítica de todo el planeta derramara ríos de tinta sobre la multitud de aspectos formales, temas y estructuras compositivas que vertebran Aura. Vidaurre Arenas comenta que la obra «es, muy probablemente, el texto más analizado de Carlos Fuentes, pues, desde su publicación hasta el presente no se han interrumpido los artículos especializados, tesis, capítulos, libros, monografías y comentarios críticos sobre esta breve narración» (2012: 159). Es un mérito atribuible a esta novela corta ${ }^{2}$ que no extraña en absoluto. Carlos Fuentes, el autor, siempre se caracterizó por ser «escritor prolífico, intelectual polifacético, batallador incansable» (Ordiz Vázquez, 2005: 25), por lo que en las páginas de su producción se ve reflejada una escritura nada sencilla, repleta de fragmentos autobiográficos, ideologías y referencias intertextuales que a menudo yacen ocultos en una narración aparentemente sencilla. Su vida estuvo jalonada de numerosos viajes, lo que le permitió conocer medio mundo, gracias al trabajo diplomático que desempeñaron sus padres, y desarrollar una notable conciencia política, junto con una sensibilidad histórico-cultural hacia sus raíces y las de su vetusta patria mexicana ${ }^{3}$. El apego a los antiguos orígenes se torna eje central en muchos de sus relatos. Sin embargo, Aura se merece un discurso aparte. Publicada en 1962, en ella se abordan temas vinculados al patrón gótico, que se entremezclan con la escritura tradicional del cuento de horror.

Hay muchos estudios en torno a los componentes nucleares de esta novela corta. Gutiérrez Mouat, por ejemplo, hace hincapié en la coherencia estructural en toda la narrativa de Fuentes,

\footnotetext{
${ }^{1}$ «¿Se vio nunca en el baile un talle más ceñido? // Su falda exagerada, de un ancho majestuoso, // se abate sobre un pie seco y largo, metido // en chapín elegante, como una flor precioso [...] ¿Vienes a perturbar con tu mueca imponente // la fiesta de la Vida? ¿O un deseo de ayer, // espoleando aún tu osamenta viviente, // candoroso te empuja al Sabbat del Placer? // Al cantar de violines y el brillar de bujías, // ibuscas ahuyentar tu burlona pesadilla // y vienes a pedir a un torrente de orgías // que refresque el infierno que en tu corazón brilla?» (Baudelaire, 2014: 338-341).

${ }^{2}$ Las propuestas de definición relativas a la extensión de esta composición constan de múltiples posibilidades, dependiendo del criterio clasificatorio que varios críticos han adoptado, nouvelle, novella, relato extenso o novela corta. En este trabajo, nos decantamos por las dos últimas opciones; a partir de esta nota, alternaremos sendas categorizaciones a lo largo del análisis.

${ }^{3}$ A este respecto, remitimos al examen biográfico de Ordiz Vázquez (2005: 19-25).
} 
insistiendo especialmente en tres características de Aura que estructuran el armazón de su redacción, que son el deseo, el motivo histórico y la dialéctica sí mismo/otro (2004: 298-299), además de exaltar lo uncanny (lo perturbador), que se propone como emblema de la designación de una víctima masculina, dando así un vuelco considerable a la literatura gótica tradicional, en la que es la mujer el blanco de los ataques físicos y mentales (2004: 304-305). Genaro Pérez coincide con esta inversión de papeles, postulando que el de Fuentes es un gótico con rastros jocosos y de subversión (1997: 11-12). Alazraki discrepa en el afán de relacionar dicha estética con lo fantástico en Aura, pues lo perturbador en esta obra no tiene necesariamente como finalidad producir terror, sino más bien adquiere tintes poéticos (1982: 95-96). Rodríguez añade que la casa es un elemento activo de la narración y encarna la naturaleza laberíntica del inconsciente, si bien no compartimos su idea del espacio interno como refugio (2006: 19-20). Por su parte, Gordillo ahonda en la dualidad gótico-simbolismo de la casa en el corpus de Fuentes (2014: 233-237).

A esto se añade la temática de la brujería medieval, lo que hace de la composición un ensamble homogéneo, un punto de unión de dos culturas, la europea y la hispanoamericana, con un constante homenaje a la literatura finisecular del siglo XIX. El denso sustrato de lecturas previas, del cual surgió la creación de Fuentes, supuso un gran reto para la crítica universal, que en muchas ocasiones ha alcanzado un nivel extremado de elucubraciones sobre qué o quién hubiese inspirado al autor mexicano a la hora de redactar Aura. Tanto Manuel Durán (1973: 78-86) como Jaime Alazraki (1982: 95-98) pusieron en tela de juicio el empeño en sistematizar todas y cada una de las posibles referencias artísticas, históricas y culturales localizables en este relato extenso. De todos modos, esto demostraría que inquirir sobre Aura con exhaustividad es una tarea muy problemática. Por ende, pretendemos en este artículo limitarnos a detectar los elementos esotérico-fantásticos más llamativos presentes en la obra, sin excusar una mirada crítica respecto de algunas de las fuentes clave que constituyen un texto de los más conocidos y valorados en el panorama literario global.

\section{Resortes fantásticos y primeras vacilaciones}

Al hojear las primeras páginas, nos topamos con dos fragmentos que introducen el texto magistralmente traducidos por Fuentes - extraídos de la obra francesa La bruja, cuyo autor, Jules Michelet, nos presenta la figura emblemática y enigmática de la mujer bruja (2014: 29-30). Palabras clave como «madre de la fantasía» y «segunda visión» (Fuentes, 1994b: 13) proporcionan algunos indicios sugerentes sobre el poder innato de la mujer y su habilidad para manipular al género masculino, que serán elementos esenciales en el desarrollo de la trama. El hombre poco o nada puede hacer frente a semejante hechicera; al fin y al cabo, «los dioses son como los hombres: nacen y mueren sobre el pecho de una mujer» (Fuentes, 1994b: 13). Además, si se conociera de antemano el trabajo de Michelet, el título mismo podría sugerir una referencia al halo demoniaco desprendido por las poseídas, lo que resaltaría una vez más la atmósfera sacrílega en la que se verá involucrado el protagonista. La alusión directa a ello se lee en otro punto del escrito: «Y cuanto más miserable es el 
cuerpo, más se agita el demonio. Sobre todo, la mujer está habitada, hinchada por estos tiranos, que la llenan de un aura infernal, haciéndola pecar y desesperándola» (Michelet, 2014: 47). A falta de conocimientos previos, tanto el título como la citación podrían conducir al lector hacia una trampa interpretativa. Lo confirmarían los primeros pasajes, cuando aparece un hombre cuya insignificancia le otorgaría el derecho de protagonizar cualquier composición de sesgo realista. Pero es justamente este elemento lo que caracteriza el género fantástico. La narración se abre con la delineación de un personaje común, con un trabajo corriente y una vida rutinaria ${ }^{4}$. En este caso, el protagonista es un historiador en busca de un empleo más rentable.

El estilo personal de Fuentes se manifiesta ya desde el comienzo al utilizar el «tú», dirigiéndose directamente al protagonista y evitando detenerse en la descripción del lugar donde el hombre lee el anuncio, despachándola con pocos detalles. Un exordio ex abrupto que se despoja de todo adorno lingüístico y participa de los pensamientos del protagonista. Conviene dudar sobre cuál sería la verdadera función de esta voz externa: ¿en verdad lo es, es decir, desempeña el papel de narrador omnisciente y casi compasivo, o simplemente representa la parte recóndita de su mente, en la que se anidan las reflexiones más críticas y sinceras sobre su condición de vida y sus acciones? Como si fuese otro yo, parece acompañar la experiencia vivida por este personaje y seguir el compás de su estado anímico hasta el ambiguo final de la obra. Podría incluso constituirse como elemento premonitorio del destino final que le aguarda. Concordando con esta hipótesis, se podría detectar un ligero alejamiento entre el narrador y el protagonista, como si el primero estuviese advirtiendo al historiador del peligro desde el principio, para luego cerrar la narración con la rendición total del personaje. Prescindiendo de la conclusión de la narración, el «tú» utilizado deja intuir que puede ocurrir algo interesante en la monotonía existencial de nuestro historiador. Intriga al lector, le anima a seguir leyendo a la vez que el protagonista se deja atraer por el prometedor anuncio. Es fácil de entender cómo el protagonista se ve interesado por el anuncio, puesto que lo ha leído «en este cafetín sucio y barato» y que él es un «historiador cargado de datos inútiles, acostumbrado a exhumar papeles amarillentos, profesor auxiliar en escuelas particulares, novecientos pesos mensuales» (Fuentes, 1994b: 13).

Utilizando un exiguo número de palabras se nos presenta el perfil del personaje, con poco dinero y aún menos entusiasmo por su vida. Con todo, el protagonista da continuas muestras de raciocinio a la hora de enfrentarse con lo absurdo y dicha habilidad se contrapone reiteradamente a los acechos seductores de las dos mujeres. Una lucha constante que produce un desdoblamiento entre lo racional y lo instintivo, que le confiere más profundidad a la personalidad del personaje. Su actitud recuerda a los personajes de la literatura policial, en la que la trama va desarrollándose en función de los descubrimientos estremecedores del protagonista e induce a que el lector participe de esta perturbación anímica (Ordiz Vázquez, 2009: 124). No ofrece el menor resquicio de duda la averiguación del

\footnotetext{
${ }^{4}$ Roas evidencia lo restringido que resulta la definición de Todorov sobre la producción de lo Unheimlische. No se debe únicamente a la vacilación, sino más bien a la irrupción de lo sobrenatural en el mundo real, algo que no tiene ninguna explicación racional (2001: 18). Se colige, pues, que lo trivial que denota la realidad anodina de Felipe Montero acentúa el efecto perturbador de lo fantástico, ya que el realismo es un elemento imprescindible, sin el cual no podría subsistir (2001: 24).
} 
principio medular de la vacilación; más que el personaje en sí, tiene que sentirla el lector (Todorov, 2001: 54).

Al recorrer el trayecto hacia la dirección indicada, el paulatino cambio estético de los edificios a medida que Felipe Montero, el protagonista de la narración, se va acercando, deja manifiesto un aviso de la presencia de otro plano de realidad. Los «viejos palacios coloniales» indican una alienación gradual del área moderna de la ciudad, un aislamiento espacio-temporal avalado por el comentario «siempre has creído que en el viejo centro de la ciudad no vive nadie» (Fuentes, 1994b: 14). El punto álgido se alcanza cuando Felipe llega a su destino: «Las sinfonolas no perturban, las luces de mercurio no iluminan, las baratijas expuestas no adornan ese segundo rostro de los edificios. [...] las ventanas ensombrecidas por las cortinas verdosas» (Fuentes, 1994b: 14).

La puesta de relieve de lo sombrío y lo desadornado, la falta de luz y de sonidos contribuyen a perfilar la dimensión atemporal que envuelve el lugar del futuro empleo de Felipe. El encuentro entre las dos realidades se realiza a través de un objeto, la manija de la puerta en el zaguán, emblemático por dos razones: 1) el desplazamiento de lo real a lo irreal convencionalmente se verifica a través de algo material, un elemento cuya existencia pervive en el límite de los dos mundos; 2) simbólicamente, la manija en sí es una clave de acceso y su función cobra mayor relevancia por el aspecto canino con el que se presenta ante los ojos del perplejo historiador. La sonrisa acogedora imaginada por él hace de contrapunto al terror que los perros guardianes suelen causar, según el imaginario colectivo. Y en este caso también, la manija cinocéfala sirve de Cerbero benigno (teniendo en cuenta que ha sido invitado a entrar a través de otro objeto catalizador, el periódico) y cede el paso al hombre. Algunos especialistas plantean la idea según la cual la simbología prehispánica está presente en Aura de manera contundente. Para ellos, el espacio fronterizo que la cabeza perruna simboliza haría referencia también a la concepción cosmológica de los mayas y los nahuas, dado que el can tenía un papel religioso importante (Calvo Oviedo, 2009: 69). Taggart coincide con esta visión; en la mitología azteca, el dios de la muerte, Ah Puch, «frecuentemente iba acompañado de un perro» (1983: 210). De todas maneras, al considerar que en Aura se homenajean patrones literarios europeos, puede que estas teorías carezcan de fundamento. A diferencia de otros escritos de Fuentes, en este, prima la influencia de corrientes procedentes del viejo continente, según leemos en el ensayo que compuso el propio autor (1994c).

La separación de la confortable realidad hacia lo desconocido y el cruzar del umbral se cumplen con una hesitación casi premonitora: «Y antes de entrar miras por última vez sobre tu hombro, frunces el ceño porque la larga fila detenida de camiones y autos gruñe, pita, suelta el humo insano de su prisa. Tratas, inútilmente de retener una sola imagen de ese mundo exterior indiferenciado» (Fuentes, 1994b: 14). Al cerrar la puerta, se cierra también el pasado, la existencia previa de Felipe y muchas certidumbres mediante las que pudiera buscar apoyo racional ${ }^{5}$. Asimismo, el propio autor de la novela corta señala la trascendencia del acto de Felipe al relatar un diálogo con Luis Buñuel, que comenta, parándose debajo del dintel de su casa, «¿y si al cruzar un umbral pudiésemos recuperar de un golpe la juventud, ser viejos de un lado de la puerta y jóvenes de nuevo apenas la cruzamos?» (Fuentes,

\footnotetext{
${ }^{5}$ Sobre la fractura entre dimensiones externa e interna véase Oliveros García (2017: 379-380).
} 


\section{Tropelías. Revista de Teoría de la Literatura y Literatura Comparada, 32 (2019)}

Atrapado en ensoñaciones mesméricas. Estudio de los elementos esotérico-fantásticos en Aura...

1994c: 279. Énfasis nuestro). La hipótesis del pasaje brusco de la senectud a la juventud se asemeja al planteamiento diegético de Aura no solo por el movimiento crucial del estudioso, sino también por los lindes difusos que separan edad real y edad anhelada establecidos por la protagonista femenina de la novela corta, como veremos más adelante.

\section{Esoterismo y manipulaciones sensoriales}

Atravesar el sombrío callejón da la idea de un ritual iniciático que se cumple con el dominio de las tinieblas que devoran la luz del día. Con esta imagen llamativamente gótica se enfatiza nuevamente la separación de dos mundos. Para llegar al fondo del patio oscuro y subir la escalera que culmina con el ingreso a la habitación de la dueña de la mansión (Consuelo Llorente, viuda de un general), necesitará seguir las instrucciones de una voz misteriosa y contar los peldaños. La mecánica del rito, pues, vuelve a protagonizar estas primeras páginas, pero será solo el principio del abandono progresivo a la voluntad ajena, dado que los constantes asaltos a la parte racional de la mente de Felipe no le darán tregua, hasta quebrantar sus últimas defensas. El uso de la razón de Felipe es antitético al manejo de filtros y conjuros de la misteriosa anciana; en conformidad con este juego dicotómico de poderes, el propio apellido del historiador, Montero, remite a la idea de un cazador perspicaz y apto para actividades diurnas, que «entronca con la actividad cinegética evocada por Michelet para caracterizar al varón» (Sanmartín Ortí, 2004: 701). La paulatina obnubilación de su habilidad perceptiva prosigue con su equivocación en creer tocar la mano de la dueña de la casa en vez de la coneja Saga. Este, al parecer, es un nombre antiguo cuyo origen se remonta a la tradición romana, conforme a lo que adecuadamente explica Cicerón en el De divinatione: «Sagire enim sentire acute est; ex quo sagae anus, quia multa scire volunt, et sagaces dicti canes. Is igitur qui ante sagit quam oblata res est, dictur praesagire, id est futura ante sentire» (CIC. div. I, 65) ${ }^{6}$.

El poder de la adivinación, grabado en las letras del nombre de la coneja, se camufla detrás de las líneas de la narración y se añade a otras manifestaciones de brujería que operan a escondidas de Felipe. ${ }^{7}$ En cuanto a la intertextualidad con el folklore mesoamericano, «Saga es lo que los indígenas

${ }^{6}$ «Porque 'tener olfato' es percibir con agudeza. Por eso se dice 'tienen olfato' las ancianas, porque saben, según creen ellas, muchas cosas, y por eso se dice que los perros tienen olfato. Por tanto, se dice que 'presagia' el que es capaz de 'oler' una cosa antes de producirse, esto es, el que presiente el futuro» (Cicerón, 1999: 101).

${ }^{7}$ Con todo, es importante precisar que había una distinción rotunda entre las denominadas striges, figuras poderosas y malévolas, y las sagae, ancianas cuya sabiduría aspiraba al vaticinio. En un trabajo sobre esta temática, Paule facilita una explicación cabal de la nomenclatura asociada al mundo mágico en época romana, consignando que «the Latin language is uncharacteristically rich when it comes to describing witches» (2014: 745). En el caso de Cicerón, el término saga se asocia a un don meramente pragmático; las ancianas (anus) adquieren una capacidad perceptiva superior, merced a su sabiduría. Por su parte, Columela rechaza la positividad de una intuición extraordinaria, condenando las prácticas divinatorias por desviar a los ingenuos hacia un camino de corrupción del espíritu. En su Res rustica, a la hora de proporcionar consejos dirigidos a los capataces, aconseja que «haruspices sagasque, quae utraque genera vana superstitione rudis animos ad inpensas ac deinceps ad flagitia conpellunt, ne admiserit» (COLVM. 1, 8, 6). En castellano: «No admitirá adivinos ni hechizeras; unos y otras son gentes que, sirviéndose de una superstición sin fundamento, empujan a los espíritus simples a hacer gastos, seguidos de acciones infamantes» (Columela, 2004: 163). El experto agronómico agrupaba en el mismo conjunto tanto a las sagae como a las haruspices, determinando un alejamiento conceptual de las sagae de Cicerón, como bien indica Paule (2014: 747). Estas últimas debían su nombre al hecho de que mostraban una habilidad similar al perro en presentir el peligro; de ahí que su condición de «sagaces» — del verbo sagere, husmear con atino- haga referencia 
mesoamericanos llamarían el nagual, es decir la parte animal que todo ser humano posee, lo que afecte a uno afectará también al otro» (Calvo Oviedo, 2009: 65) ${ }^{8}$. En síntesis, el vocablo podría ser una puerta de acceso a estéticas escandinavas, un homenaje al acto mismo de componer historias. Por lo tanto, volviendo al roce de la mano de Felipe con el picaporte canino del vestíbulo, nos cercioramos de que, al igual que un escudo familiar, es representativo del legado místico y ancestral que Consuelo, al practicar ritos mistéricos, ha asimilado. A medida que Felipe Montero comparte su existencia con la de Consuelo Llorente, la confusión provocada entre real-irreal, fantasía-entorno concreto no será unilateral, sino que mostrará una multiplicidad de facetas que amenazarán asiduamente el juicio del protagonista y que comprenderá todos los sentidos perceptivos. En las siguientes líneas, abordaré este aspecto nodular de la composición del relato.

Empezando por el oído, el maullido de algunos gatos que Felipe cree oír desde un indefinido rincón de la morada le hace dudar de si es un producto de su mente o es real (Fuentes, 1994b: 20). Pero poco después, la señora Consuelo añadirá más misterio e irrealidad negando la presencia felina en su casa (Fuentes, 1994b: 23). A continuación, la tranquilidad interior de Felipe se desvanece nuevamente por la irrupción de aquel sonido escalofriante:

Has terminado de afeitarte cuando ese maullido implorante y doloroso destruye el silencio de la mañana. Llega a tus oídos con una vibración atroz, rasgante, de imploración. Intentas ubicar su origen: abres la puerta que da al corredor y allí no lo escuchas: esos maullidos se cuelan desde lo alto, desde el tragaluz (Fuentes, 1994b: 24) ${ }^{9}$.

Respecto del olfato, es muy impactante la imagen de los felinos envueltos en llamas: «Se revuelcan envueltos en fuego, desprenden un humo opaco, un olor de pelambre incendiada» (Fuentes, 1994b: 24). El hedor a quemado estimula la percepción del entorno por parte de Felipe, añade repulsión y horror a una escena ya de por sí atroz y, sobre todo, hace que la alucinación presupuesta adquiera aspectos mucho más concretos.

En lo que atañe al tacto, al margen del ya mencionado episodio con la coneja, se realiza otro contacto mucho más significativo, una muñeca de trapo. Es un objeto que representa el momento conclusivo del proceso de manipulación mental, cuyos amagos se perciben a partir del despertar de un

a las capacidades sensoriales de los perros. Es incuestionable la predominancia de las mujeres en este ámbito, aunque tenían un papel marginal respecto de la adivinación oficial (Montero Herrero, 1994: 44-45). En definitiva, cada autor interpretaba el concepto de mujer dotada de poderes sobrenaturales de manera distinta. Un nutrido grupo de investigadores ha proporcionado sugestivas suposiciones en torno a la palabra «saga» y el animal que lleva dicho nombre. Frecuente es la asociación de la fertilidad de los conejos con el acto de engendrar a Aura (Montoya Sors, 2002: 35; Habra: 2005, 185; Marquina Sánchez, 2008: 12).

${ }^{8} \mathrm{Al}$ mismo tiempo, hay que recordar que «saga es el nombre de ese género literario que, del siglo VIII hasta el siglo XIII, convierte a Islandia en una ventana que se abre hacia el interior de la Europa nórdica medieval, en narrativas que despliegan ante nuestra lectura, dioses, familias, mujeres y hombres cuyas vidas se entretejen en aventuras y en dramas» (Marquina Sánchez, 2008: 13).

${ }^{9}$ Un trabajo brillante de Patricia Hart nos aclara que los felinos no solo tienen un papel central en el texto, sino que revelan una importante deuda literaria que Fuentes contrajo respecto de una novela paródica de principios del siglo XX. Se trata de ¿Quién disparó? (1907), de Joaquín Belda. En concreto, hay un episodio en el que el protagonista entra en una casa oscura y aparece una mujer misteriosa, Stella, cuyo nombre evoca a aquel personaje infantil y seductor que aparece en Great Expectations (1860-1861) de Dickens (1987: 41-47). No sería muy descabellado, pues, presumir que se creara una conexión intertextual entre Aura y estas dos obras. 
sueño aterrador; Felipe está «aturdido, hambriento» y demuestra una falta de cuidado en su aseo cotidiano que contradice la característica meticulosidad de su actitud racional: «Te lavas la cara, los dientes con tu brocha vieja embarrada de pasta verdosa, te rocías el pelo sin advertir que debías haber hecho todo esto a la inversa» (Fuentes, 1994b: 31). Durante la cena, se perfila una escena típicamente onírica. La muñeca, como muchos otros objetos presentes en el relato, se convierte en catalizador del estado hipnótico en el que se encuentra el protagonista. Sabido es que el sueño y la pesadilla son herramientas cardinales para los espiritistas, ya desde los tiempos ancestrales. Aludiendo a la vida, a la muerte o a irrefrenables deseos, es palmario que las imágenes evocadas por el subconsciente provocan sugestiones estremecedoras que otorgan una importancia primordial a las manifestaciones oníricas (Castiglioni, 1972: 55-57). Una vez más, Carlos Fuentes exhibe una maestría narrativa extraordinaria jugando con términos pertenecientes al campo semántico de la hipnosis y de las hechicerías, junto con palabras que expresan movimientos rígidos y mecánicos:

\footnotetext{
Y al lado de tu plato, debajo de la servilleta, ese objeto que rozas con los dedos, esa muñequita endeble, de trapo, rellena de una harina que se escapa por el hombro mal cosido [...] Comes mecánicamente, con la muñeca en la mano izquierda y el tenedor en la otra, sin darte cuenta, al principio, de tu propia actitud hipnótica, entreviendo, después, una razón en tu siesta opresiva, en tu pesadilla, identificando, al fin, tus movimientos de sonámbulo con los de Aura, con los de la anciana: mirando con asco esa muñequita horrorosa que tus dedos acarician, en la que empiezas a sospechar una enfermedad secreta, un contagio. La dejas caer al suelo. Te limpias los labios con la servilleta (Fuentes, 1994b: 31-32).
}

Es patente la labor de la mujer anciana para dominar la mente del historiador, y sobre todo la forma con la que consigue atraparlo en su red de encantos, obligándole a que su rol protagónico quede avasallado por la voluntad de Consuelo. En efecto, «Felipe becomes a secondary character in a history not foreclosed but animated by dark forces that modernity, in its compulsion to forget stirs and releases» (Gutiérrez Mouat, 2004: 304). De acuerdo con la cita inicial de esta novela corta, resumida en la frase «la mujer intriga y sueña» (Fuentes, 1994b: 13), el poder de la bruja es de sesgo mesmeriano, y a través del contacto se crea un paralelismo entre Aura/muñeca/Felipe Montero. Los tres quedan interconectados por medio de hilos invisibles, manejados por Consuelo, y su influjo mágico se infiere por lo maquinal de sus gestos. Hemos de destacar la manera personalísima de Consuelo en servirse de una técnica que se valoró especialmente en el siglo XIX; es cierto que Gauthier cataloga el magnetismo humano de mesmerismo, con miras de separar su definición de la que se refiere al magnetismo animal, que él indica con el neologismo zoomagnetización (1856: 187). No obstante, se trata de un rubro que arduamente entroncaría con el arte de la esposa del general. Lo ejerce un ser cuyas connotaciones psicofísicas trascienden el estatus de mujer y la convierten en una entidad híbrida, en conexión permanente con lo animalesco. Por lo tanto, su mesmerismo es de sesgo zoo-antropomórfico, que se aleja de cualquier taxonomía convencional.

Examinando los avatares gustativos, nos percatamos de que «riñones, tomates, vino» (Fuentes, 1994b: 32) son los únicos alimentos y bebidas admitidos en las cenas de aquella casa. Siendo la reiteración del menú una implícita alusión a otro ritual místico, puede que las entrañas y el alcohol se vinculen con tradiciones esotéricas, cuyo fin sería tomar posesión de la voluntad de las víctimas 
mediante la asimilación de dichos víveres. A confirmación de ello, Mendoza asevera que, con algunas plantas, ya de desde la Baja Edad Media «se fabricaba el Vinum Sahbati que de acuerdo al sexo creaba un íncubo o un súcubo, con quien la persona se entregaba a goces sexuales» (1989: 198). Es fácil deducir, pues, que las plantas y las raíces podridas anteriormente observadas por Felipe (1994b: 14) tienen una finalidad prefijada. Por otro lado, Caro Baroja apunta que hay un caso significativo en la tradición literaria clásica de una encantadora anciana que ansía poseer el cuerpo de un joven. Se trata de una «mujer ya talluda que obra movida por un erotismo exacerbado por la edad, la edad crítica de la sexualidad para hombres y mujeres», y es justamente Canidia, una bruja citada en los Epodos de Horacio, que desea que su antiguo amante, Varo, restablezca su relación amorosa con ella (Hepod. 5, 17-25, en Caro Baroja, 1997: 77-78).

La vista es innegablemente el sentido que sella tajantemente la total y absoluta rendición de Felipe, y no podría ser de otra manera. Desde los antiguos cuentos y baladas épicas a la literatura romántica, pasando por la lírica trovadoresca, la mirada ha jugado un papel fundamental a la hora de transmitir los influjos, benignos o ruines, de amor u odio, ventura o maldición y por supuesto para atraer indisolublemente a la víctima de dicho poder. En efecto, cuando la habilidad de razonamiento de Felipe le advierte de que algo anómalo está ocurriendo a su alrededor, le ocasiona hesitación a la hora de elegir si quedarse en la casa de Consuelo y aceptar el trabajo o hacer caso a su intuición y salir de aquel mundo falaz y engañoso lo antes posible. Sus titubeos se disipan en el momento en que aparece de repente Aura. Serán sus ojos que, abriéndose despacio, como soltando un arma prohibida y cautivadora, le convencerán para quedarse:

La muchacha mantiene los ojos cerrados, las manos cruzadas sobre un muslo: no te mira. Abre los ojos poco a poco, como si temiera los fulgores de la recámara. Al fin, podrás ver esos ojos de mar que fluyen, se hacen espuma, vuelven a la calma verde, vuelven a inflamarse como una ola: tú los ves y te repites que no es cierto, que son unos hermosos ojos verdes idénticos a todos los hermosos ojos verdes que has conocido o podrás conocer. Sin embargo, no te engañas: esos ojos fluyen, se transforman, como si te ofrecieran un paisaje que sólo tú puedes adivinar y desear. - Sí. Voy a vivir con ustedes (Fuentes, 1994b: 18).

El cromatismo proteico de los ojos de Aura perturba a Felipe y motiva una serie de reflexiones contradictorias; serán portavoces de un duelo entre racionalidad e instinto que no terminará hasta que él logre oponerse a las tentaciones y los encantos que las dos mujeres le lanzan a lo largo de este relato extenso. El íride refleja la voluntad plasmadora de Consuelo y es quintaesencia de su embrujo. Incluso es posible ampliar la hipótesis de un dinamismo relacionado con el espectro de los colores al contemplar cómo estos se fusionan y originan nuevas tonalidades de gran carga simbólica:

Si se acepta a partir de este instante que Aura es una proyección de Consuelo, entonces el color amarillo de las pupilas de Consuelo parece haberse avivado por el color rosa de las del animal para dar luz al color verde seductor de la mirada de Aura. Asimismo, los tres folios están atados por una cinta amarilla, azul y roja al final. La evolución del amarillo al rojo parece transitar por la aleación eventual del amarillo con el azul. El color verde que resultaría evocaría la aparición ilusoria de Aura y de su papel transitorio en insuflar vida a la pareja (Habra, 2005: 193).

A su vez, Montoya Sors sintetiza eficazmente la trascendencia del verde en Aura (2002: 30). La transmutación marina que el protagonista observa es indicio de la existencia de otra dimensión, 


\title{
Tropelías. Revista de Teoría de la Literatura y Literatura Comparada, 32 (2019) \\ Atrapado en ensoñaciones mesméricas. Estudio de los elementos esotérico-fantásticos en Aura...
}

interpolada en el microuniverso que la anciana, materialización femenina del concepto demiúrgico formulado por Platón, ha forjado. Es este universo aquello que más eficazmente obliga a la sumisión. Y la mirada hipnotizadora de la joven volverá a acechar los sentidos de Felipe en más de una ocasión; por ejemplo, durante la primera cena:

\begin{abstract}
Beben ese vino particularmente espeso, y tú desvías una y otra vez la mirada para que Aura no te sorprenda en esa impudicia hipnótica que no puedes controlar. Quieres, aun entonces, fijar las facciones de la muchacha en tu mente. Cada vez que desvíes la mirada, las habrás olvidado ya y una urgencia impostergable te obligará a mirarla de nuevo (Fuentes, 1994b: 20).
\end{abstract}

La obsesión por cruzar su mirada con ella se explicita nuevamente con otro intercambio de ojeadas:

Al fin levanta la mirada y tú vuelves a dudar de tus sentidos, atribuyes al vino el aturdimiento, el mareo que te producen esos ojos verdes, limpios, brillantes, y te pones de pie, detrás de Aura, acariciando el respaldo de madera de la silla gótica, sin atreverte a tocar los hombros desnudos de la muchacha, la cabeza que se mantiene inmóvil. Haces un esfuerzo para contenerte, distraes tu atención escuchando el batir imperceptible de otra puerta, a tus espaldas, que debe conducir a la cocina, descompones los dos elementos plásticos del comedor: el círculo de luz compacta que arroja el candelabro y que ilumina la mesa y un extremo del muro labrado, el círculo mayor, de sombra, que rodea al primero (Fuentes, 1994b: 21).

La atención prestada en los detalles descriptivos remite a lo mágico y a lo satánico y sufraga la representación de una seducción sacrílega, cuya víctima no consigue escaparse. Todos estos elementos de manipulación psicológica conllevan la presencia de matices fantásticos sutilmente ocultados debajo de la aparente atmósfera hogareña y acogedora en la que se ve involucrado Felipe Montero. En la mente del historiador se insinúan lenta pero inexorablemente, perjudicando sus recursos intelectuales e impidiéndole razonar con lucidez. Un episodio clave que subraya dicha situación ocurre en el momento en que Aura aparece por primera vez:

Y la muchacha está allí, esa muchacha que no alcanzas a ver de cuerpo entero porque está tan cerca de ti y su aparición fue imprevista, sin ningún ruido — ni siquiera los ruidos que no se escuchan pero que son reales porque se recuerdan inmediatamente, porque a pesar de todo son más fuertes que el silencio que los acompañó- (Fuentes, 1994b: 17).

Es preciso considerar en este fragmento la etérea esencia de la joven, cuyos pasos silenciosos enfatizan la idea de una figura fantasmal, una presencia diáfana que revela una coincidencia entre su naturaleza y el nombre en sí, Aura. Su condición impalpable vislumbra una conexión con el Felipe del comienzo, cuya inconsistencia se revelaba por su insignificante existencia, dando lugar a un diseño geométrico de reminiscencia borgiana ${ }^{10}$. Asimismo, cabe evidenciar otro aspecto más interesante sobre este personaje; al margen del (presunto) vínculo de parentesco con la tía Consuelo, ¿qué es lo que de verdad se conoce acerca de la vida de la joven? Sustancialmente nada. Su familia, sus años anteriores a la estancia en calle Donceles, incluso sus aficiones quedan todos desconocidos. La incorporeidad que la identifica se manifiesta en su totalidad. Ella es la personificación de la imposibilidad de

\footnotetext{
${ }^{10}$ Conviene recordar que los escritos de Jorge Luis Borges formaban parte del gran número de obras previamente leídas por Fuentes (Durán, 1973: 84).
} 
encontrar una verdad unívoca e ilustradora que ayude a Felipe a encontrar la solución del enigma de las dos mujeres. El protagonista no descubre la realidad de los hechos por medio de sus investigaciones, sino que acaba por ser víctima sacrificial de la verdad misma y quedará atrapado en la red de engaños tejida por Consuelo, hasta llegar a identificarse por completo con el marido fallecido cuarenta años antes (Fuentes, 1994b: 40). Pérez efectivamente habla de una resignación como consciencia de la impotencia frente a la superioridad de fuerzas sobrenaturales, que se traduce en la rendición frente al dominio de Consuelo (1997: 18) ${ }^{11}$. Al centrar nuestro examen en la anciana viuda, invirtiendo así nuestra perspectiva, notamos cómo lo inmaterial se conecta con el dolor por la pérdida del amado marido. En efecto,

[...] Fuentes recrea el carácter fantasmático de la experiencia amorosa que vincula con el proceso melancólico que resulta de la pérdida a través de la muerte del objeto de amor, el cual culmina en el fantasma del deseo que encarna el personaje que da nombre a la novela y que desempeña una función mediadora, pues une a los amantes desafiando el tiempo y la condición de su propia mortalidad. En esta perspectiva la muerte del ser amado genera un estado de melancolía que se asocia a un proceso erótico que establece un comercio ambiguo con los fantasmas del deseo -Aura-Consuelo (Albín, 2006: 129. Énfasis nuestro).

El término «fantasmático», pues, se reviste de connotaciones psicológicas, acorde a la definición que ofrece el Diccionario de la Lengua Española: «Dicho de una representación mental imaginaria: Provocada por el deseo o el temor» (Real Academia Española, 2018: s. v.). Al ser Aura una proyección de la obsesión de Consuelo por revivir lo que ya ha perdido, el autor lo expresa articulando un discurso narrativo en el que

[...] lo que es real pierde su realidad y es suplantado por lo irreal que experimenta una transformación hasta ocupar la categoría de lo real, es decir, ante la pérdida del objeto de amor, el amante o la amante convertido en sujeto melancólico reacciona negando el mundo externo y se refugia en una psicosis alucinatoria del deseo (Albín, 2006: 129).

\section{Reflexiones conclusivas}

Sugerente, cautivadora, a veces trastornadora esta novela corta no deja de sorprender por el constante juego de roles que se instaura entre los tres personajes, dando lugar a un extraño ménage que ignora las normas convencionalmente aceptadas por la sociedad, también supeditadas al poder de la bruja. Incluso el tiempo y su eterno fluir se arrodilla simbólicamente frente al dominio mágico de Consuelo. Las leyes dictadas por el principio de panta rei pierden su importancia, se anulan porque ya no tienen su función de medición, puesto que el propio tiempo está subyugado. Y desde luego la construcción del cronotopo de Aura ofrece un amplio abanico de teorías; especialmente, el desarrollo temporal que va enhebrando los episodios de la vida de Felipe en la casa ha despertado el interés de muchos estudiosos. Para citar algunos, Montoya Sors recalca la conexión cronológica entre el tiempo pasado del general Llorente y el actual de Montero, lo que daría lugar a una yuxtaposición de planos

${ }^{11}$ A los cuantiosos trabajos publicados sobre la dualidad, el desdoblamiento Aura/Consuelo Felipe/general Llorente, Alazraki contrapone su teoría basada en el concepto de superimposition, que involucra a «two characters who unfold continually and are present and past at the same time, old age and youth» (1982: 99). 
temporales (2002: 36-38). Por su parte, Ángel Náter compara las ruinas urbanas, tópico literario del gótico tradicional, con la idea de decadencia y decrepitud que se ve reflejada en las vetustas paredes de la casa de Consuelo, determinando las consiguientes ponderaciones acerca del tiempo como recordatorio de la fragilidad humana (2004: 77). De la insignificancia del tiempo canónico nos habla Oliveros García, puntualizando que el protagonista «acepta resolutivamente que Aura es/fue/será y no es/fue/será Consuelo, que él es/fue/será y no es/fue/será el General» (2017: 381). Incluso podemos localizar los momentos en los que se asiste a una transgresión temporal, con la causa que se pospone al efecto, permitiendo así a Consuelo compartir el mismo cronotopo de su creación, Aura (Bejel y Beaudin, 1978: 466).

Carlos Fuentes enfatiza la inutilidad de marcar un momento cronológico definido y la relaciona con la importancia mucho más relevante del lector, quien en un paralelismo con la hechicera de Aura adquiere un poder creador que supera el límite de la mera interpretación de un texto:

Y, en última instancia, es el lector quien le da presencia a una novela en el acto mismo de la lectura. La escritura de un libro es finita, su lectura puede ser infinita. Y en la lectura se cumplen en verdad las premisas de LA EDAD DEL TIEMPO: todo sucede hoy, el pasado es la memoria hoy, el futuro es el deseo hoy» (Fuentes, 1994a: 9).

El lector, en el acto de la lectura, es un brujo que plasma la realidad a su antojo, así como la mujer anciana vive una y otra vez un pasado que ya no volverá a acontecer. Analizando el texto con arreglo a dicho eje interpretativo, Felipe Montero ya no es el verdadero protagonista, sino Consuelo; todo estaba preestablecido desde el momento en que el historiador leyó aquel anuncio, dejándose conducir por el poderío de la bruja. Felipe, a la fuerza, acaba siendo otro muñeco, que se une a los muchos objetos guardados en el mostrador de aquel cuarto sombrío, un recordatorio simbólico del poder y del anhelo al recuerdo característicos de Consuelo. Es de mayor calado y eficacia, pues, el acto de remodelación de la trama de Aura por parte de quienes hojean las páginas de este relato extenso, junto con las inquietudes de los comentaristas al aplicar sus tesis y postulados. La panoplia de ideas y propuestas aclarativas es el móvil de un dinamismo que compensa la aniquilación de la voluntad de Montero. Gutiérrez Mouat esclarece certeramente la perplejidad sobre el heroísmo y la integridad del protagonista masculino de Aura; si por un lado «el historiador deja que su sentido de responsabilidad profesional se interponga en su impresa liberadora», por otro «esta falta de iniciativa es un índice de la paralización volitiva del personaje. La hechicería de Consuelo/Aura hace mermar progresivamente la voluntad de Felipe» (1985: 47). Por añadidura, en palabras de Higashi,

[...] la obra só1o vive en esa compleja interrelación con los comentarios de sus lectores contemporáneos. Aura, su crítica, no son — serán, fueron - sino muestras de la terca permanencia del pasado en el presente: Consuelo y Aura, obra y reflejo, en la vida de aquel Felipe Montero, historiador (1999: 81-82).

En conclusión, la posibilidad de una multiplicidad de interpretaciones, el peso alegórico del tiempo, el papel fundamental del lector a la hora de considerar el texto según sus personales reflexiones, todo concurre a declarar Aura el fruto de una labor magistral llevada a cabo por un escritor del calibre de Carlos Fuentes. La originalidad del autor mexicano se infiere del uso personalísimo de fuentes 
literarias pertenecientes a multitud de tradiciones, encajándolas en un texto que atrapa la atención del lector en la trama de Aura, de la misma manera por la que Felipe Montero y su identidad previa se diluyen en el enredo mágico de Consuelo Llorente. La anciana, pues, dispone de poderes que traspasan los lindes de lo conocible y su talento brujeril refuerza su identidad de mujer activa y poderosa, debilitando a la vez la razón, una capacidad antonomásticamente masculina. En este breve ensayo hemos esbozado un esquema de las fases durante las que opera lo esotérico que, en coalescencia con la vertiente fantástica, configura el núcleo de la obra. La antagonista no quita su máscara de aparente inocencia sin asegurarse previamente su victoria absoluta. Su arte de entrampar se torna infalible en una gradación aumentativa, desde un estadio embrionario - cuando ya la penetración en el territorio de Consuelo encierra cierto peligro - hasta una madurez alcanzada por los asaltos sensoriales, coadyuvada por aquel magnetismo hipnótico que se teorizó en el XIX.

Aun así, el mesmerismo no fue la única práctica que arraigó en los ambientes culturales de la época. En México, aquello que se estimaba de gran valor científico era el espiritismo, especialmente en las décadas finales decimonónicas. Tal como asienta Leyva, el éxito de la revista La Ilustración Espírita, junto con la presencia de una red nacional de comunidades de espiritistas, denota la obstinación en aquel periodo por confiar en la existencia de un más allá (2005: 14). Su afinidad con la creación de Fuentes reside en su oposición a lo real, un conflicto destinado a la derrota: «La realidad superaría todo. Era una lucha contra el tiempo y la realidad. Buscaba salvar a los espíritus y al mundo espiritual para que tanta realidad no nos abrumara. Su labor también pereció rendida ante la realidad. El día de hoy hay más realidad que espíritus» (Leyva, 2005: 16). Irónicamente, pese a los impedimentos impuestos por el dominio masculino y el consiguiente confinamiento en un edificio ruinoso, Consuelo Llorente sí consigue encontrar su libertad y hacer que su espíritu se salve del peso abrumador de una realidad obligada.

\section{Referencias bibliográficas}

AlazRAKI, J. (1982): «Theme and System in Carlos Fuentes' Aura», en R. Brody y C. Rossman, eds., Carlos Fuentes: A Critical View. Austin, University of Texas Press, pp. 95-105.

Albín, M. C. (2006): «El fantasma de Eros: Aura de Carlos Fuentes», Atenea: revista de ciencias, artes y letras, núm. 494, pp. 127-142.

ÁNGEL NÁTER, M. (2004): «La imaginación enfermiza: la ciudad muerta y el gótico en Aura de Carlos Fuentes», Revista Chilena de Literatura, núm. 64, pp. 73-89.

BAUdElAIRE, C. (2014): Las flores del mal. Edición bilingüe. Trad. M. J. Santayana. Madrid, Vaso Roto.

BeJEl, E. y BEAUdin, E. (1978): «Aura de Fuentes: La liberación de los espacios simultáneos», Hispanic Review, vol. 46, núm. 4, pp. 465-473. 
Calvo Oviedo, M. (2009): «Lo mesoamericano en Aura de Carlos Fuentes: una propuesta de interpretación», Cuadernos Inter.c.a.mbio sobre Centroamérica y el Caribe, vol. 6, núm. 7, pp. 55-88.

Caro Baroja, J. (1997): Las brujas y su mundo. Madrid, Alianza.

Castiglioni, A. (1972): Encantamiento y magia. Trad. G. Pérez Enciso. México D. F., Fondo de Cultura Económica.

Ciceron, M. T. (1977): «De divinatione», en W. Ax, ed., M. Tulli Ciceronis scripta quae manserunt omnia. Fasc. 46, De divinatione. De fato. Timaeus, Stuttgart, B. G. Teubner, pp. $1^{\text {b}}-129^{\mathrm{b}}$.

— (1999): «Sobre la adivinación», en Á. EsCOBAR, ed., Sobre la adivinación. Sobre el destino. Timeo. Madrid, Gredos, pp. 33-270.

Columela, L. J. M. (1977): On agriculture. Vol. I, Res rustica I-IV, en H. B. AsH, ed., William Heinemann, Loeb Classical Library. Londres, Harvard University Press.

(2004): «La labranza», en J. I. GARCíA ARMENDÁRIZ, ed., Libro de los árboles. La labranza: libros I-V. Madrid, Gredos, pp. 123-415.

DurÁn, M. (1973): «Aura o la obra perfecta», en Tríptico mexicano: Juan Rulfo, Carlos Fuentes, Salvador Elizondo. México D. F., Secretaría de Educación Pública, pp. 78-133.

Fuentes, Carlos (1994a): «La edad del tiempo», en El mal del tiempo, vol. I. Madrid, Alfaguara, p. 9. (1994b): «Aura», en El mal del tiempo, vol. I. Madrid, Alfaguara, pp. 13-41.

(1994c): «Cómo escribí algunos de mis libros», en El mal del tiempo, vol. I. Madrid, Alfaguara, pp. 277-287.

GAUTHIER, A. (1856): Tratado práctico del magnetismo, o resumen de todos los principios y procedimientos usados hasta el día. Madrid, Imprenta Miguel González.

GoRDiLlo, A. (2014): «Los fantasmas de la casa. Reflexiones sobre el gótico en la obra de Carlos Fuentes», Badebec, vol. 3, núm. 6, pp. 227-253.

GutiérRez MouAt, R. (1985): «Carlos Fuentes y el relato fantástico», Modern Language Studies, vol. 15, núm. 1, pp. 39-49.

(2004): «Gothic Fuentes», Revista Hispánica Moderna, vol. 57, núms. 1-2, pp. 297-313.

HABRA, H. (2005): «Modalidades especulares de desdoblamiento en "Aura" de Carlos Fuentes», Confluencia, vol. 21, núm. 1, pp. 182-194.

HART, P. (1987): «Nuevas fuentes sobre Carlos Fuentes. Un antepasado sorprendente de "Aura"», Chasqui: revista de literatura latinoamericana, vol. 16, núms. 2-3, pp. 37-49.

HigASHI, A. (1999): «Fiesta mexicana: primera recepción de Aura», Signos Literarios y Lingüísticos, vol. 1, núm. 1, pp. 66-87.

Leyva, J. M. (2005): El ocaso de los espíritus. El espiritismo en México en el siglo XIX. México, Cal y Arena.

MARQuina SÁncheZ, I. (2008): «El Mundo Fantástico de Aura: Cosas, Bestias y Otros Símbolos», Subje/Civitas, vol. I, núm. 2, pp. 1-17. 
MendozA, M. (1989): «"Aura" de Carlos Fuentes: Un aquelarre en la calle donceles 815», Anales de literatura hispanoamericana, núm. 18, pp. 191-202.

MiCHELET, J. (2014): La bruja: Un estudio de las supersticiones en la Edad Media. Trads. R. Lajo y M. V. Frígola. Madrid, Akal.

Montero Herrero, S. (1994): Diosas y adivinas. Mujer y adivinación en la Roma antigua. Madrid, Trotta.

MontoyA SoRs, C. (2002): «De "Aura" en adelante: el tiempo reconstruido por Carlos Fuentes», Rassegna iberistica, núms. 75-76, pp. 27-41.

Oliveros GARCÍA, J. (2017): «Explorando el espacio en los textos fantásticos hispanoamericanos: Aura de Carlos Fuentes», en S. SÁncheZ-HernándeZ y A. Agraz OrTIZ, eds., Topografías literarias. El espacio en la literatura hispánica de la Edad Media al siglo XXI. Madrid, Biblioteca Nueva, pp. 375-384.

ORDIZ VÁZQUEZ, F. J. (2005): El mito en la obra narrativa de Carlos Fuentes (2 ${ }^{a}$ Edición). León, Universidad de León.

- (2009): «Incursiones en el reino de lo insólito. Lo fantástico, lo neofantástico y lo maravilloso en la narrativa mexicana contemporánea», en J. C. GonZÁlez BoIXo, ed., Tendencias de la narrativa mexicana actual. Madrid-Frankfurt, Iberoamericana-Vervuert, pp. 123-140.

PAUle, M. T. (2014): «QVAE SAGA, QVIS MAGVS: On the Vocabulary of the Roman Witch», Classical Quarterly, vol. 64, núm. 2, pp. 745-757.

PÉREZ, G. J. (1997): «La configuración de elementos góticos en "Constancia," Aura y "Tlactocatzine, del jardín de Flandes" de Carlos Fuentes», Hispania, vol. 80, núm. 1, pp. 9-20.

REAL ACADEMIA ESPAÑOLA (2018): Diccionario de la lengua española, disponible en https://dle.rae.es/?w=diccionario [consultado 08/03/2019].

RoAs, D. (2001): «La amenaza de lo fantástico», en D. RoAs, ed., Teorías de lo fantástico. Madrid, Arco/Libros, pp. 7-44.

Rodríguez, M. del M. R. (2006): «Seducción gótica vs modernidad en Aura de Carlos Fuentes», Revista de literatura mexicana contemporánea, núm. 30, pp. 17-26.

SANMARTÍn ORTí, P. (2004): «Aura: análisis de lo fantástico en la obra de Carlos Fuentes», en V. ARENAS LOZANO et al., eds., Líneas actuales de investigación literaria: estudios de literatura hispánica. Valencia, Universitat de València, pp. 699-708.

TAGGART, K. M. (1983): «El tema de la muerte en Aura», en El tema de la muerte en tres novelas mexicanas. Madrid, Playor, pp. 193-226.

Todorov, T. (2001): «Definición de lo fantástico», en D. RoAs, ed., Teorías de lo fantástico. Arco/Libros, Madrid, pp. 47-64.

Vidaurre Arenas, C. V. (2012): Las continuidades ocultas. Estudio contextual de una obra de Carlos Fuentes. Tomo I. Saarbrücken, Editorial Academia Española. 